\title{
Non-linear Control of a Piezoelectric Two Stage Servovalve
}

\author{
Johan Persson, Andrew Plummer, Chris Bowen and Phil Elliott* \\ Department of Mechanical Engineering, University of Bath, Bath, United Kingdom \\ E-mail: ljp46@bath.ac.uk, A.R.Plummer@bath.ac.uk, C.R.Bowen@bath.ac.uk \\ * Moog Aircraft Group, Moog Controls, Ashchurch, Tewkesbury, United Kingdom \\ E-mail: pelliott2@moog.com
}

\begin{abstract}
This paper describes an algorithm to control a two stage hydraulic servovalve designed for aerospace applications. The valve has a piezoelectric ring bender actuating a first stage spool with a significant amount of overlap to reduce internal leakage. The piezoelectric ring bender is a less complex and lighter alternative to a conventional torque motor. The second stage has electrical instead of the conventional mechanical feedback. The control algorithm includes compensation for the first stage spool overlap, piezoelectric hysteresis compensation and a feed forward term. The hysteresis compensation is based on a relatively simple Bouc-Wen hysteresis model that is able to significantly reduce the amount of first stage hysteresis. The overlap compensation, increasing the gain in the overlap region, reduces the impact of amplitude change and increases performance. It can also reduce any asymmetry in the system. The controller has a superior performance compared to a PI controller, as demonstrated experimentally using step and frequency responses.
\end{abstract}

Keywords: piezoelectric actuator, two-stage servovalve, spool, hysteresis compensation.

\section{Introduction and Valve Prototype}

This paper describes a control algorithm used to control the position of the main stage in a two stage servovalve designed for aerospace flight control applications. It has a piezoelectric ring bender actuating the pilot stage spool and a second stage spool with electrical feedback.

A two-stage servovalve converts an electrical signal into the position of a fluid-metering spool via a hydraulic amplification stage [1]. Such a servovalve is usually used to control flow to the hydraulic actuator where high performance motion control is required.

In a typical single-aisle airliner there are approximately 40 hydraulic servovalves, which are the key control component in electrohydraulic actuation for primary flight control, landing gear deployment, on-ground braking and steering. Key drivers for new aerospace hydraulic servovalve designs are to reduce weight, reduce manufacturing cost, and improve efficiency through reduced internal leakage. For example, by reducing the internal leakage of a servovalve approximately 2200 USD per valve per year of fuel cost could be saved by the airline companies [2]. To reduce the internal leakage a small spool with significant overlap was used for the pilot stage.

In a conventional valve, the first (or pilot) stage refers to the torque motor and either nozzle-flapper, jet pipe or deflector jet amplifier, and provides the actuation to move the main spool (second stage). Torque motors can be time-consuming and expensive to set-up, requiring significant manual intervention [3]. If not adjusted precisely the first stage amplifier may not provide stable operation, and there is a continual flow loss (and power loss) through the nozzles or jet. An alternative approach is required providing a more cost effective design, which is amenable to automated manufacture.

Smart materials, and in particular piezoelectric ceramics, are a possible alternative potentially providing high forces and fast response times [4], [5]. Stack and bending actuators have been extensively researched [6]. The relatively new multilayer three wire piezoelectric ring bender is a type of bending actuator, which is a flat annular disc that deforms in a concave or convex fashion depending on the polarity of the applied voltage, see fig. 1 (c) [6], [7]. Such an actuator configuration has been chosen for first stage actuation since it exhibits a greater displacement than a stack actuator of the same mass, and an increase in stiffness in comparison to similar size rectangular bimorph type bender, resulting in a larger force output. 


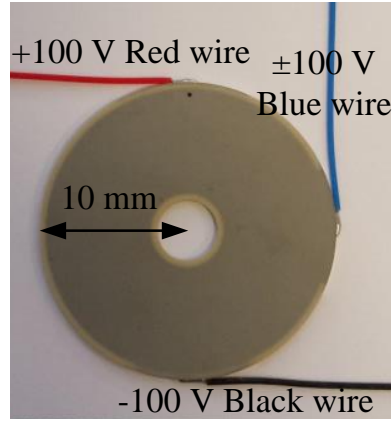

(a)

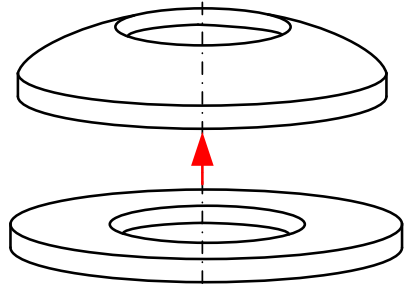

(c)

Figure 1. (a) Noliac piezoelectric ring bender (b) Microscopic section of a piezoelectric ring bender (c) Piezoelectric ring bender deformation

A Noliac CMBR08 multilayer, three wire piezoelectric ring bender is used for actuating the first stage in the prototype valve. The piezoelectric ring bender has a $40 \mathrm{~mm}$ diameter and $1.25 \mathrm{~mm}$ thickness, a free displacement of $\pm 115 \mu \mathrm{m}$ and a blocking force of $\pm 39 \mathrm{~N}$. Figure 1 (a) shows the ring bender with its three wire electrical connection. The bender is made up of multiple $67 \mu \mathrm{m}$ thick lead zirconium titanate (PZT) piezoelectric ceramic layers. To apply the necessary electric field across the piezoelectric ceramic and thereby actuate the device, silver palladium electrodes are located between each layer, which can be seen as light lines in fig. 1 (b). In order to deflect the ring bender in both directions the electrodes are combined into three groups, as shown in fig. 1 (b) [8].

The concept for the first stage is to use the ring bender to actuate a small spool, see fig. 2 , with significant overlap to reduce the internal leakage. The piezoelectric ring bender moves the spool to control the flow to the second stage.

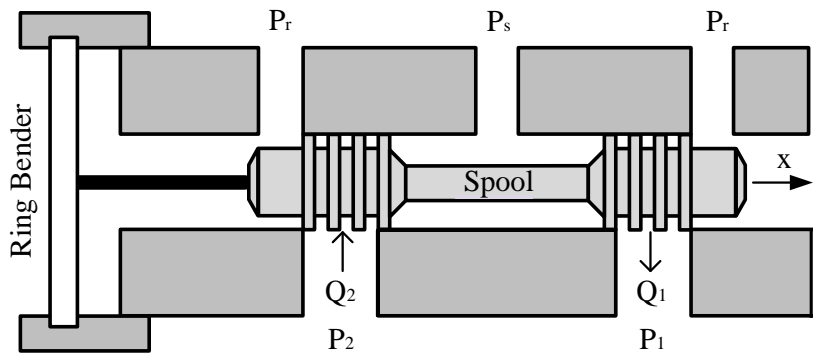

Figure 2. First stage concept.
Electrical second stage feedback allows a sophisticated digital controller to be implemented and will be more effective to counteract disturbances [9], compared to valves with mechanical feedback.

The piezoelectric actuated valve prototype was built and tested on a dedicated test bench. The second stage titanium alloy spool housing was made through Additive Manufacture (AM), which, enables a greater design freedom. Figure 3 shows the valve, where the first stage spool, piezoelectric ring bender and the LVDT's to obtain first and second stage position can be seen. A photograph of the valve tested with its AM second stage housing is shown in fig. 4. A circuit diagram of the system can be seen in fig. 5 .

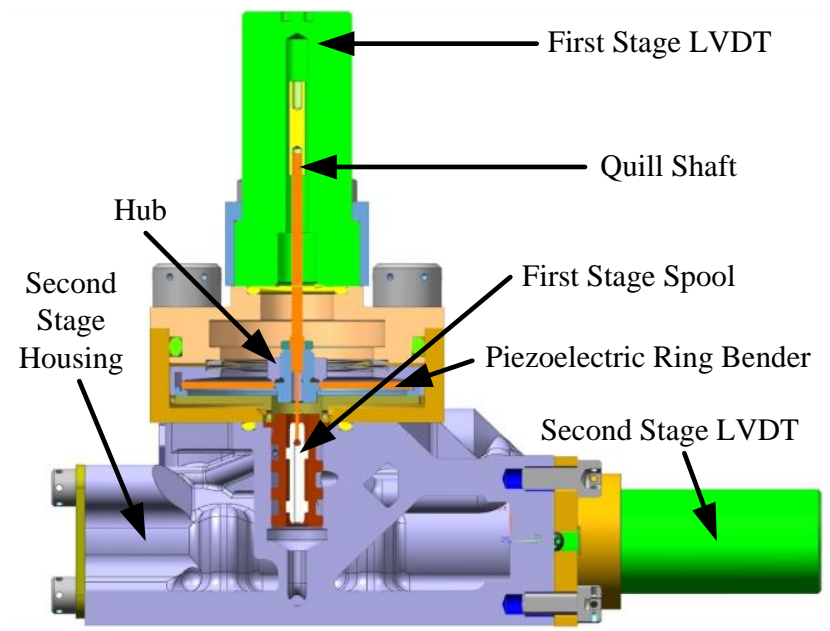

Figure 3. Cross section of the pilot stage.

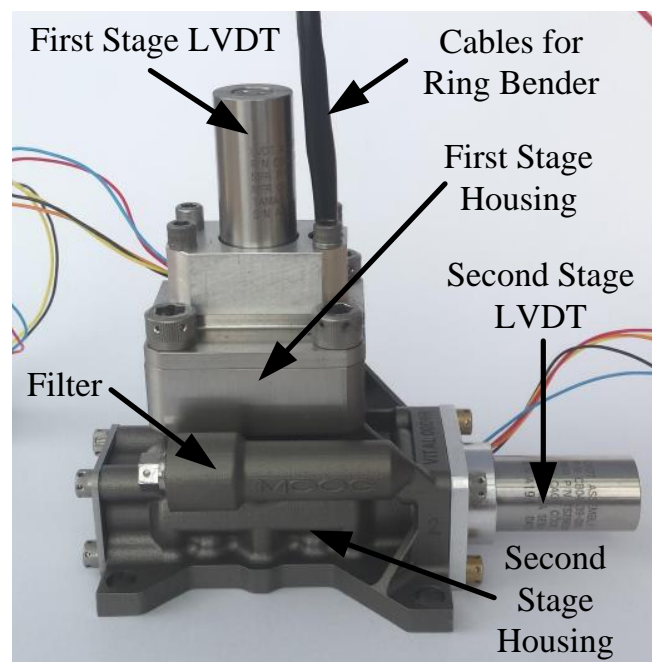

Figure 4. Photograph of the valve tested.

This paper presents a control strategy for compensating the hysteresis of the piezoelectric ring bender, without using additional sensors (such as pilot stage position feedback), which add weight, cost and complexity to the valve. The first stage LVDT in the prototype will merely be used to monitor the performance of the piezoelectric ring bender and first stage spool, and not used for control. 
The influence of a reduction of first stage piezoelectric hysteresis on the second stage positioning performance was studied. The study also includes compensation for the first stage spool overlap and implementation of a feed forward term to increase the second stage spool position response.

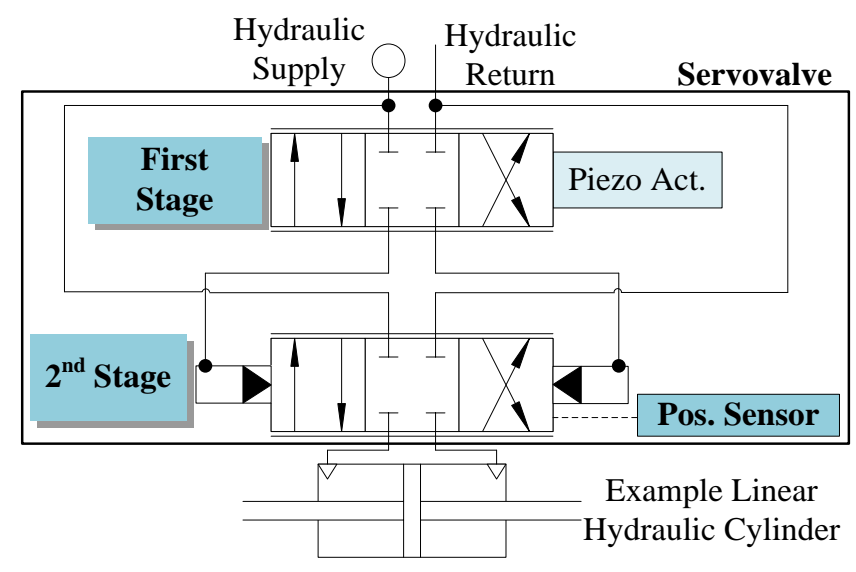

Figure 5. Internal servovalve circuit.

\section{Controller Design}

In traditional two stage servovalves with mechanical feedback and torque motor the steady state spool position is proportional to the electrical input current in the torque motor [10] [11]. This is achieved by the feedback spring exerting a feedback torque on the torque motor proportional to spool position. However, using an electrical second stage positioning feedback this is not the case.

The controller platform used for this investigation was an xPC system where a Simulink control model is automatically converted to real-time code to run on a PC target. A circuit diagram of the control setup can be seen in fig. 6. An amplifier was needed to drive the piezoelectric ring bender. The control computer was configured to record the first and second stage spool positions as well as the amplifier output voltage.

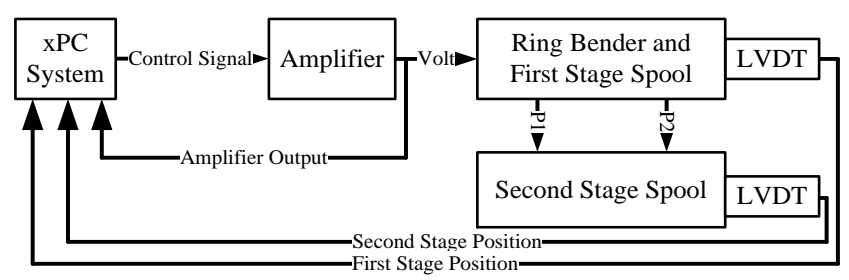

Figure 6. Circuit diagram of the control setup.

A Proportional-Integral (PI) controller is a common feedback control algorithm using Proportional, $K_{p}$, and Integral, $K_{i}$, gains as can be seen in fig. 7. Due to the piezoelectric hysteresis and a significant amount of first stage spool overlap, causing a 'dead-band', this controller not sufficient, as will be described later.

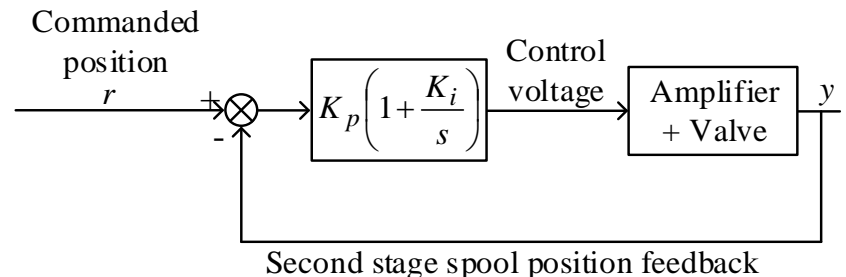

Figure 7. PI control loop.

The control algorithm proposed in this paper, see fig. 8, includes overlap compensation, hysteresis compensation and command velocity feed forward terms. The hysteresis and overlap compensation are intended to make the system more linear and the feed forward loop is to make the response faster. The controller block diagram is shown in fig. 8 .

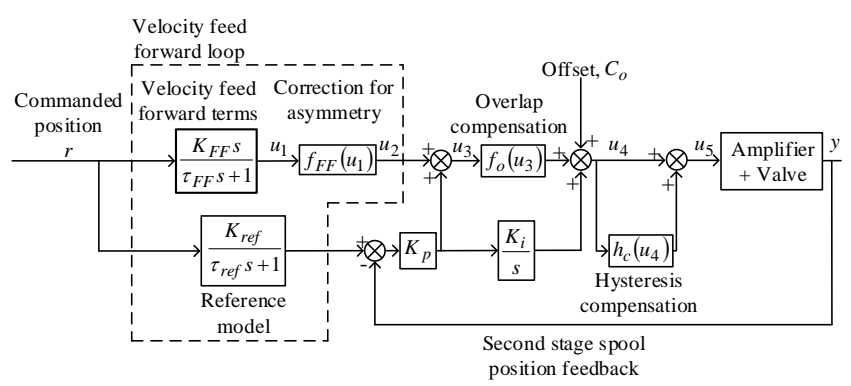

Figure 8. Proposed control algorithm.

All the parameter values used can be seen in tab. 1 .

\subsection{Hysteresis Compensation}

Previously an inverse of the more complicated PrandtlIshinskii model has been used for hysteresis compensation of a piezoelectric ring bender [12]. The Bouc-Wen model has been used previously to compensate for the hysteresis of a rectangular piezoelectric bender [13]. However, in that work only static or low frequency $(0.07 \mathrm{~Hz})$ responses were investigated.

The hysteresis compensation used for the current work is also based on a Bouc-Wen hysteresis model [14], which is a relatively simple 3-parameter model and also simple to invert to form a hysteresis compensator [13]. The Bouc-Wen model, eq. (1), has three dimensionless tuning parameters $\alpha, \beta$ and $\gamma$. The hysteresis term $n$ is the deviation away from the linear response, and $u_{3}$ is the demanded voltage from the controller (voltage after the overlap compensation and integral gain). Figure 9 shows one experimental hysteresis loop and a simulated hysteresis loop, using the Bouc-Wen model, where $n$ is subtracted from the linear response. It can be seen that the hysteresis model matches the experimental data. In the compensator, $n$ times a scaling factor, is added to the control voltage, as can be seen in eq. (2) and fig. 8 . The scaling factor, $K_{h}$ is needed to restore the correct linear gain. The three tuning parameters values can be seen in tab. 1 . 


$$
\begin{gathered}
\dot{n}=\alpha \dot{u}_{3}-\beta\left|\dot{u}_{3}\right| n-\gamma \dot{u}_{3}|n| \\
h_{c}\left(u_{3}\right)=K_{h} n
\end{gathered}
$$

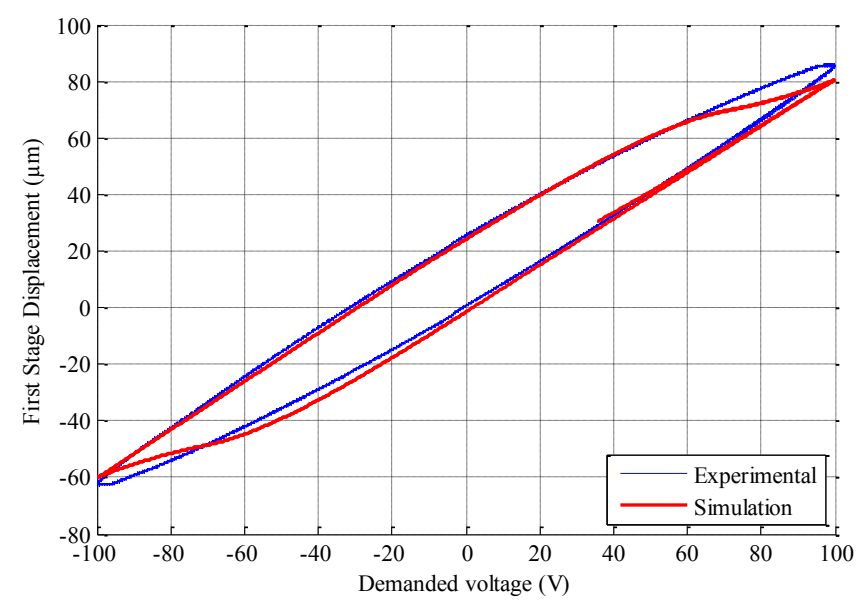

Figure 9. Experimental hysteresis loop vs simulated hysteresis loop.

Figure 10 shows two experimental hysteresis loops, one with hysteresis compensation and one without hysteresis compensation. As can be seen the hysteresis is significantly reduced.

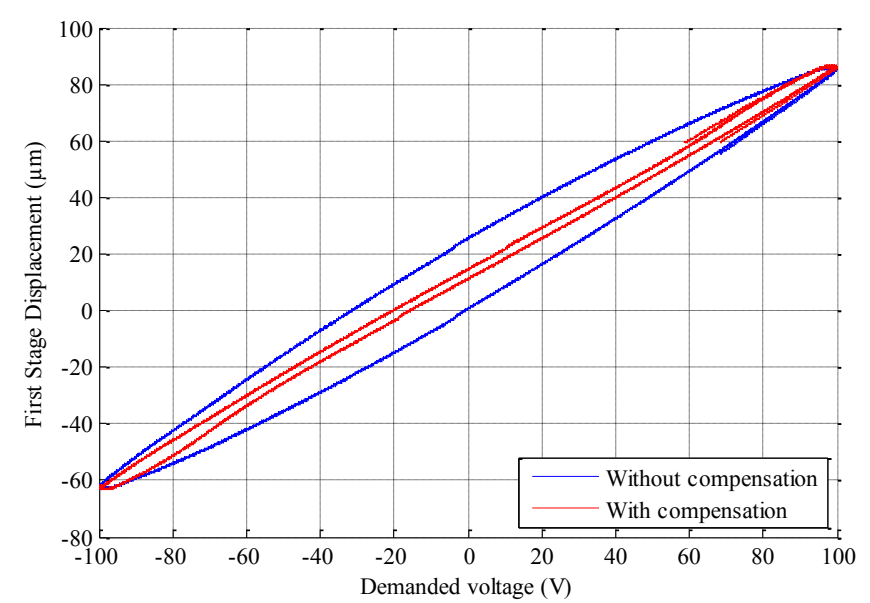

Figure 10. Experimental hysteresis compensation loop.

\subsection{Overlap Compensation}

The first stage spool is closed center with a significant amount of overlap, $\sim 20 \mu \mathrm{m}$, to reduce the internal leakage. A closed center arrangement will result in a 'dead-band' where very little flow is passing to the second stage in the overlap region [15], as can be seen in fig. 11 .

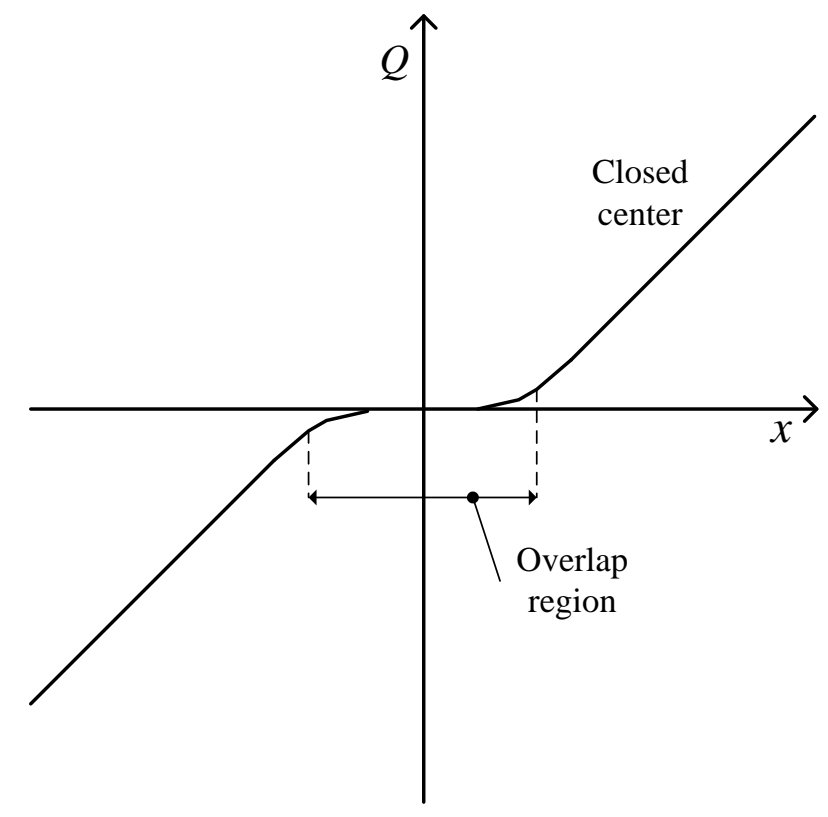

Figure 11. Flow gain for closed center spool.

To be able to linearize the system this dead-band has to be compensated for. The overlap compensation was implemented as a look-up table with a higher gain where the first stage spool was in the overlap region, see fig. 12. Figure 13 shows the measured second stage velocity versus the first stage position. The overlap compensation also compensated for some asymmetry and offset, as can be observed in fig. 13 . The offset is the difference between the electrical null for the piezoelectric ring bender and the hydraulic null of the first stage spool, seen in fig. 13, and is compensated by an offset term $C_{o}$ (fig. 8). In fig. 13 a small lag between the first stage position and second stage velocity can be observed.

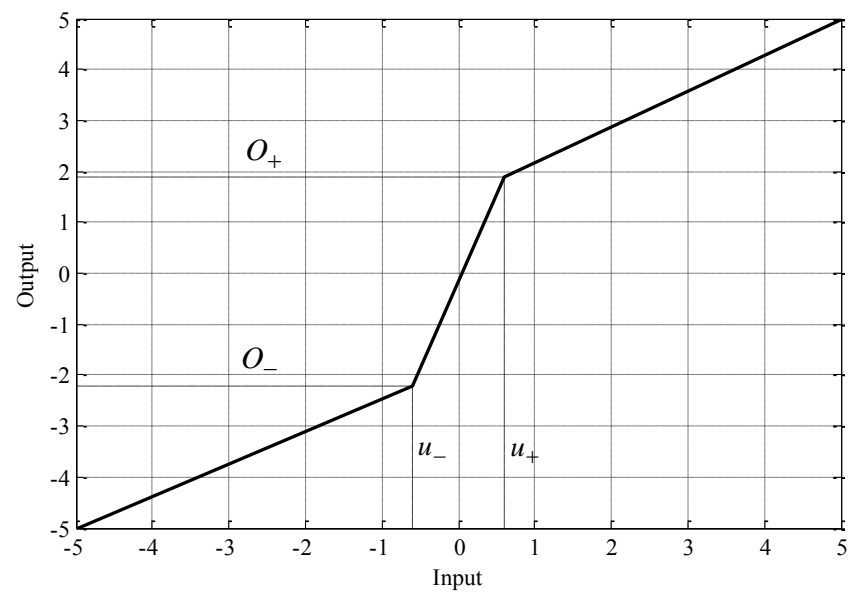

Figure 12. Overlap compensation function $\left(f_{o}\right)$ 


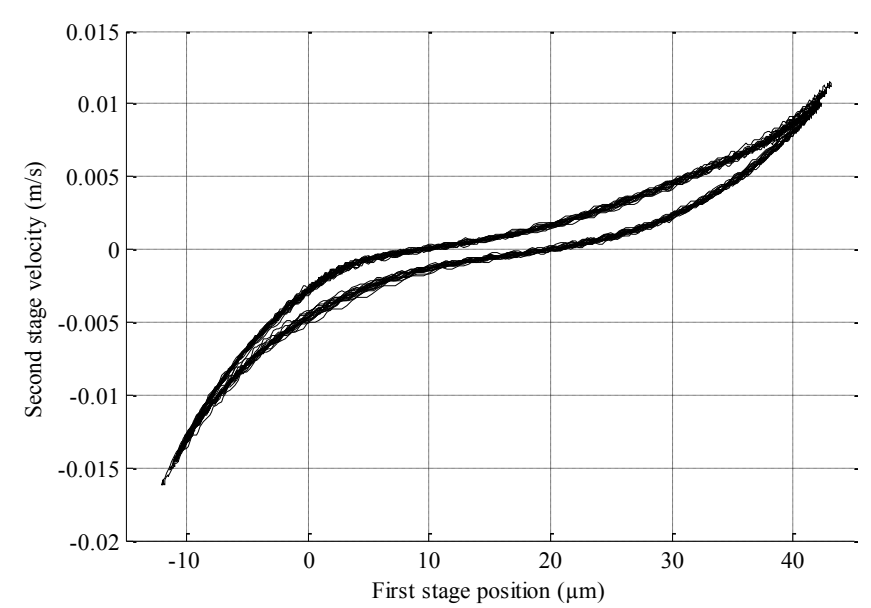

Figure 13. Velocity of the second stage spool compared to the first stage position.

\subsection{Command Velocity Feedforward}

The command velocity feedforward will speed up the dynamic response, which generally means increasing the bandwidth of the system [16]. The velocity feedforward consists of three parts, the feedforward terms, reference model and the model to correct for asymmetry in the second stage spool behavior. The feedforward command velocity is estimated by differentiated position filtered by a first order lag, as can be seen in fig. 8. The feedforward loop also compensates for velocity asymmetry in the system. The asymmetry is due to the null offset in the valve coupled to the non-linear stiffness of the piezoelectric ring bender mounting. The function $f_{F F}\left(u_{1}\right)$ term is a lookup table as shown below:

$$
\begin{gathered}
f_{F F}\left(u_{1}\right)=1.4 u_{1} \text { if } u_{1} \geq 0 \\
f_{F F}\left(u_{1}\right)=u_{1} \text { if } u_{1}<0
\end{gathered}
$$

A reference model is included as a prediction of the response of the system to the feedforward path. The feedback control thus only acts on the error between the actual spool position and the predicted position. This error can also be thought of as a disturbance observer.
Table 1. Parameter table.

\section{Parameter}

Value

\section{Hysteresis compen- sation} parameters

$\alpha$, Hysteresis tuning

$0.0017(-)$ parameter

$\beta$, Hysteresis tuning parameter

$0.00065(-)$

$\gamma$, Hysteresis tuning parameter

$0.0015(-)$

$K_{h}$, Hysteresis scaling factor

Overlap

compen-

$O_{+}$, Positive overlap

$1.9(V)$

sation

compensation output

parameters

$O_{-}$, Negative overlap

compensation output

$u_{+}$, Positive overlap

$0.6(V)$

compensation input

$u_{-}$, Negative overlap

compensation input

Feed

$K_{F F}$, Feedforward term gain

0.00005

forward

loop

parameters

$K_{\text {ref }}$, Reference model gain

$1(-)$

$\tau_{F F}$, Feedforward term lag

$0.0015(-)$

$\tau_{\text {ref }}$, Reference model lag

$0.003(-)$

Controller

$K_{p}$, Proportional gain for the

0.012

non-linear controller

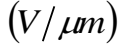

$K_{i}$, Integral gain for the non-

linear controller

$K_{p 1}$, Proportional gain for PI1

$0.05(-)$

$K_{p 2}$, Proportional gain for PI2

$0.03(-)$

$K_{i 1}$, Integral gain for PI1

$K_{i 2}$, Integral gain for PI2

$C_{o}$, Null offset comensation

$0.25(V)$ 


\section{Results}

The valve prototype with the proposed control algorithm has been tested. The effect of the different controller parts were compared. Four different controller arrangements were tested:

- Complete controller (FF+OC+HC)

- Overlap compensation (OC) and hysteresis compensation (HC)

- Overlap compensation (OC) and feed forward (FF)

- Only overlap compensation (OC).

Two different step input sizes, $60 \mu \mathrm{m}$ and $120 \mu \mathrm{m}$, were tested as well as a $30 \mu \mathrm{m}$ amplitude frequency response. The nonlinear controller was compared to the conventional PI controller of fig. 7 at the end of this section. All tests were performed at 200 bar and at an oil temperature of $39 \pm 1.5^{\circ} \mathrm{C}$.

Figure 14 shows the $60 \mu \mathrm{m}$ step response and fig. 15 shows the $120 \mu \mathrm{m}$ step response. The rise time $(0-90 \%)$ and the settling time $( \pm 5 \%)$ for both amplitudes can be seen in tab. 2 and tab. 3 .

By only compensating for the overlap the rise time is $8.2 \mathrm{~ms}$ for a $60 \mu \mathrm{m}$ step and 7.3 for a $120 \mu \mathrm{m}$ step size. The settling time for $120 \mu \mathrm{m}$ step was $57.6 \mathrm{~ms}$, but the position did not settle within $\pm 5 \%$ for the $60 \mu \mathrm{m}$ step. By having the overlap compensation and hysteresis compensation the response is quicker, but the device also experiences more overshoot. By having the overlap compensation and a feedforward term the response was even further improved. The complete controller had the overall fastest response.

The average difference between the commanded position and the actual position is $5.6 \mu \mathrm{m}$ for the $60 \mu \mathrm{m}$ step and $7.7 \mu \mathrm{m}$ for the $120 \mu \mathrm{m}$ step for the controller without hysteresis compensation $(\mathrm{OC}+\mathrm{FF})$. This can be compared to the complete controller that has a difference of $4 \mu \mathrm{m}$ for the $60 \mu \mathrm{m}$ step and $6.1 \mu \mathrm{m}$ for the $120 \mu \mathrm{m}$ step.

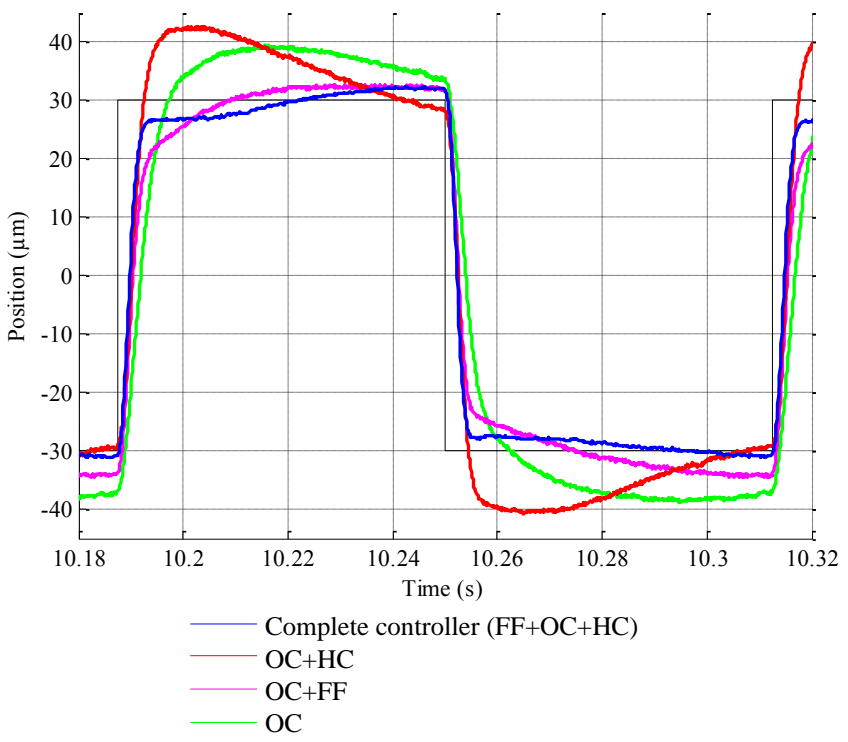

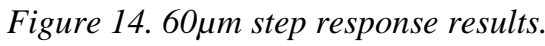

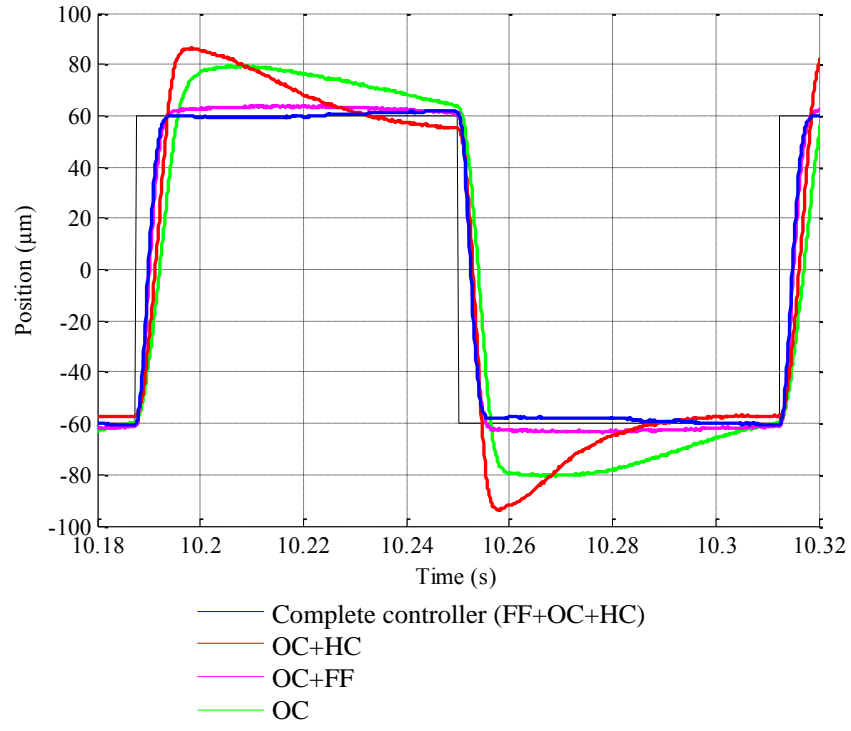

Figure 15. 120 $\mathrm{\mu m}$ step response results.

Table 2. 60 $\mathrm{um}$ step response results with different combinations of overlap compensation (OC), feed forward $(F F)$ and hysteresis compensation $(H C)$.

\begin{tabular}{|c|c|c|}
\hline 60um Step & $\begin{array}{l}\text { Rise time } \\
(0-90 \%)\end{array}$ & $\begin{array}{l}\text { Settling time } \\
( \pm 5 \%)\end{array}$ \\
\hline $\begin{array}{l}\text { Complete controller } \\
(\mathrm{FF}+\mathrm{OC}+\mathrm{HC})\end{array}$ & $4.6 \mathrm{~ms}$ & $15.7 \mathrm{~ms}$ \\
\hline $\mathrm{OC}+\mathrm{HC}$ & $4.5 \mathrm{~ms}$ & $44.6 \mathrm{~ms}$ \\
\hline $\mathrm{OC}+\mathrm{FF}$ & $10.3 \mathrm{~ms}$ & $14.9 \mathrm{~ms}$ \\
\hline OC & $8.2 \mathrm{~ms}$ & $>62.5 \mathrm{~ms}$ \\
\hline
\end{tabular}

Table 3. 120um step response results with different combinations of overlap compensation (OC), feed forward $(\mathrm{FF})$ and hysteresis compensation $(\mathrm{HC})$.

\begin{tabular}{|l|l|l|}
\hline 120 $\mathbf{\mu m}$ Step & $\begin{array}{l}\text { Rise time } \\
\mathbf{( 0 - 9 0 \% )}\end{array}$ & $\begin{array}{l}\text { Settling time } \\
\mathbf{( \pm 5 \% )}\end{array}$ \\
\hline $\begin{array}{l}\text { Complete controller } \\
(\mathbf{F F}+\mathbf{O C}+\mathbf{H C})\end{array}$ & $4.3 \mathrm{~ms}$ & $4.8 \mathrm{~ms}$ \\
\hline $\mathbf{O C}+\mathbf{H C}$ & $5.7 \mathrm{~ms}$ & $35.8 \mathrm{~ms}$ \\
\hline OC+FF & $4.9 \mathrm{~ms}$ & $5.2 \mathrm{~ms}$ \\
\hline OC & $7.3 \mathrm{~ms}$ & $57.6 \mathrm{~ms}$ \\
\hline
\end{tabular}

A frequency response test was completed with an amplitude of $30 \mu \mathrm{m}$, see fig. 16. It can be seen that in the system where the feedforward loop is included both the magnitude and 
phase lag first decrease then increase again. This is most likely due to inexact first stage overlap compensation.

It can also be seen in fig. 16 that the setup with overlap compensation and hysteresis compensation (without feedforward) has a better performance than the complete system until around $50 \mathrm{~Hz}$ for the magnitude and $30 \mathrm{~Hz}$ for the phase, but after those frequencies the complete setup performs better than the other control algorithms.
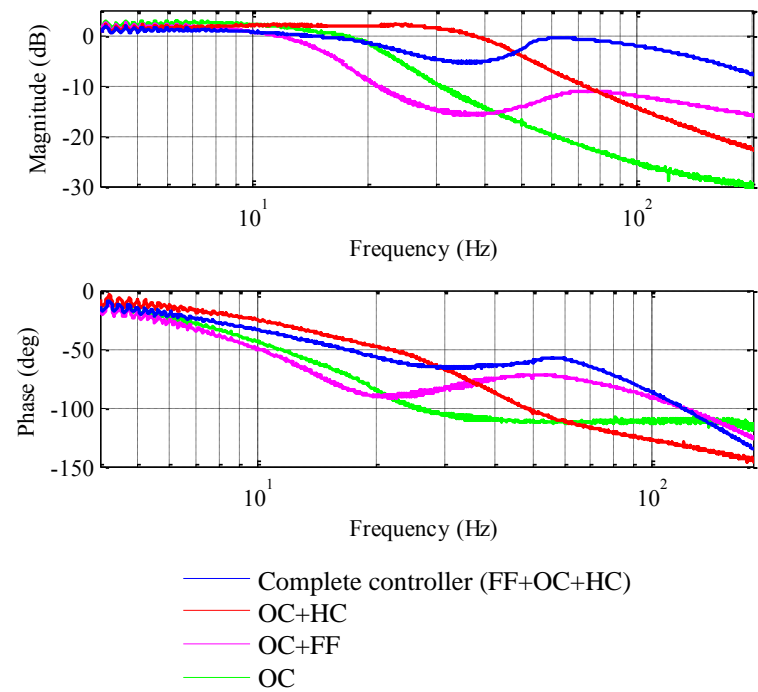

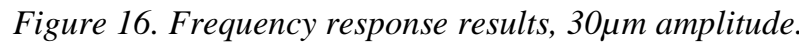

The complete non-linear controller was compared to a welladjusted conventional PI controller. Responses to steps of $60 \mu \mathrm{m}$ and $120 \mu \mathrm{m}$ were measured as well as a $30 \mu \mathrm{m}$ amplitude frequency response. Two different PI setups were tested, one was tuned to give a good response for a square wave amplitude of $30 \mu \mathrm{m}$ amplitude $(60 \mu \mathrm{m}$ step, PI1) and the second for a $60 \mu \mathrm{m}$ amplitude $(120 \mu \mathrm{m}$ step, PI2).

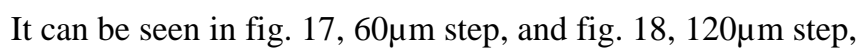
that for the same PI controller for the different amplitudes significantly different results will be obtained. It can also be observed that the proposed non-linear control algorithm is the better controller when it comes to rise time and settling time, as can be seen in tab. 4 and tab. 5, as well as being less affected by the amplitude change. The PI controller setup for a $30 \mu \mathrm{m}$ amplitude $(60 \mu \mathrm{m}$ step) did not settle within $\pm 5 \%$ of the step within $62.5 \mathrm{~ms}$ in either case.

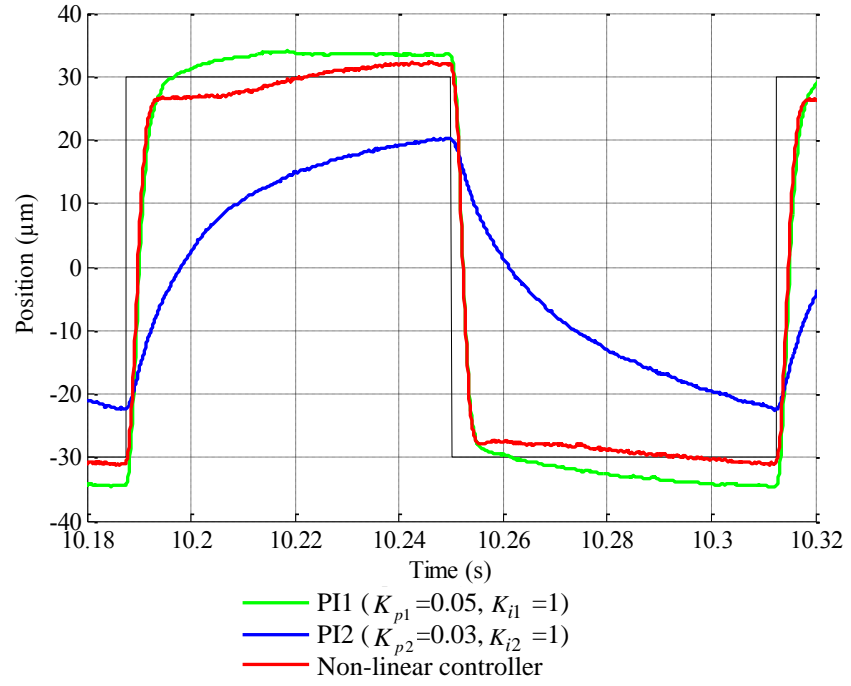

Figure 17. 60um step, PI setup vs complete non-linear control algorithm.

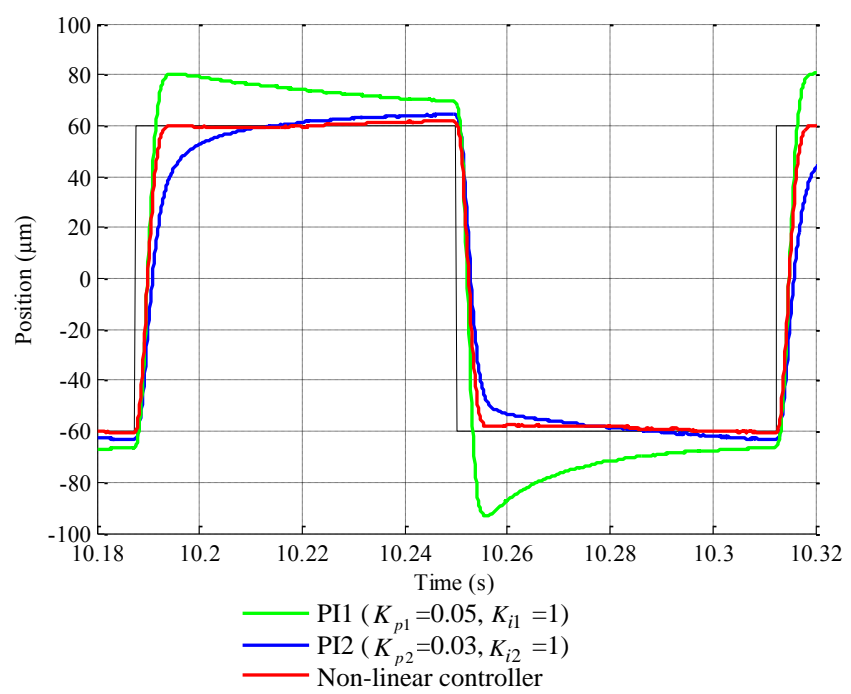

Figure 18. 120um step, PI setup vs complete non-linear control algorithm.

Table 4. PI controller, 60um step response.

\begin{tabular}{|c|c|c|}
\hline 60um Step & $\begin{array}{l}\text { Rise time } \\
(0-90 \%)\end{array}$ & $\begin{array}{l}\text { Settling } \\
\text { time } \\
( \pm 5 \%)\end{array}$ \\
\hline PI1 $\left(K_{p 1}=0.05, K_{i 1}=1\right)$ & $5.2 \mathrm{~ms}$ & $>62.5 \mathrm{~ms}$ \\
\hline $\mathbf{P I 2}\left(K_{p 2}=0.03, K_{i 2}=1\right)$ & $>62.5 \mathrm{~ms}$ & $>62.5 \mathrm{~ms}$ \\
\hline Non-linear controller & $4.6 \mathrm{~ms}$ & $15.7 \mathrm{~ms}$ \\
\hline
\end{tabular}


Table 5. PI controller, $120 \mu \mathrm{m}$ step response.

\begin{tabular}{|c|c|c|}
\hline 120um Step & $\begin{array}{l}\text { Rise time } \\
(0-90 \%)\end{array}$ & $\begin{array}{l}\text { Settling } \\
\text { time } \\
( \pm 5 \%)\end{array}$ \\
\hline PI1 $\left(K_{p 1}=0.05, K_{i 1}=1\right)$ & $3.7 \mathrm{~ms}$ & $>62.5$ \\
\hline PI2 $\left(K_{p 2}=0.03, K_{i 2}=1\right)$ & $9.4 \mathrm{~ms}$ & $14 \mathrm{~ms}$ \\
\hline Non-linear controller & $4.3 \mathrm{~ms}$ & $4.8 \mathrm{~ms}$ \\
\hline
\end{tabular}

A frequency response was completed for the two PI controllers and the non-linear controller, see fig. 19. It can be seen that the non-linear controller gives a better dynamic response particularly in terms of magnitude throughout the frequency range. Note that the low frequency phase lag evident in the PI controller response is due to the hysteresis.
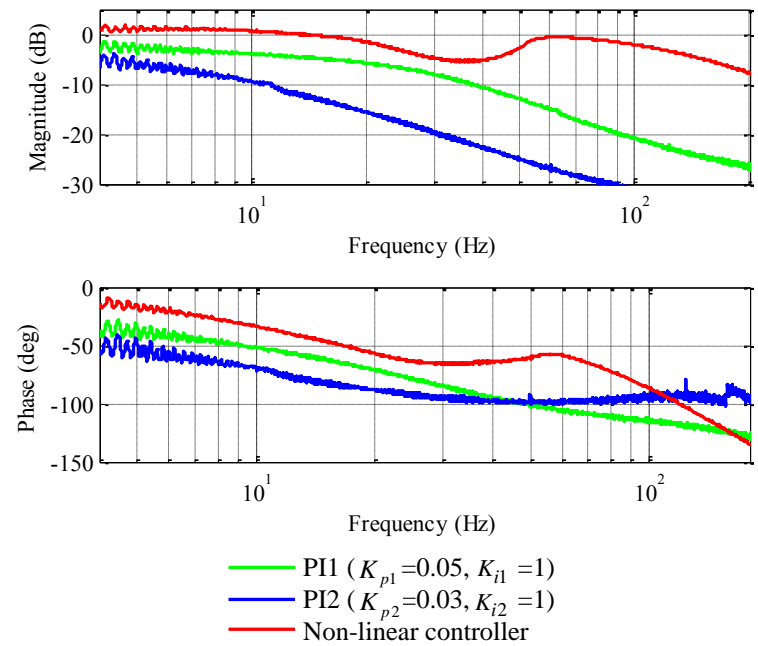

Figure 19. Frequency response of conventional PI controller vs Experimental non-linear controller.

\section{Conclusions}

A prototype low-leakage piezoelectric servovalve has been developed. For main spool position control, a conventional PI controller is sensitive to amplitude changes, due to the lack of compensation for the first stage overlap. A higher gain in the first stage spool overlap region is essential to remove this sensitivity. However, due to piezoelectric hysteresis, the relationship between the drive voltage and first stage position is not linear. Thus hysteresis compensation is required to enable effective overlap compensation. In addition, command velocity feedforward has been tested to improve the dynamic response. The complete control algorithm, with all three features, is shown to provide the fastest and most accurate response. It is shown that the non-linear controller significantly outperforms two PI controllers, which span the range of plausible proportional gain values.
Work currently ongoing:

i. Maximizing reliability of piezoelectric ring benders in aerospace hydraulic fluid.

ii. Optimization of mountings for piezoelectric ring benders.

\section{Acknowledgments}

The authors would like to thank Moog Aircraft Group, Renishaw and Innovate UK for supporting this research. Ownership of Intellectual Property described in this work is detailed in collaboration agreements for VITAL IUK project 17413-117299 and Moog-Bath PhD Studentship Agreement of $5 / 9 / 15$.

\section{References}

[1] Moog, "Servo Valves," 2017. [Online]. Available: http://www.servovalve.com/. [Accessed: 12-Jan2017].

[2] Moog, "Servovalve Leakage Fuel Costs (Moog Internal Report)," 2012.

[3] D. K. Sangiah, A. R. Plummer, C. R. Bowen, and P. Guerrier, "A novel piezohydraulic aerospace servovalve. Part 1: design and modelling," Proc. Inst. Mech. Eng. Part I J. Syst. Control Eng., vol. 227, no. 4, pp. 371-389, 2013.

[4] C. Mangeot, B. Anderssen, and R. Hilditch, "New Actuators for Aerospace," Kvistgaard, 2008.

[5] R. Le Letty, F. Claeyssen, F. Barrillot, and N. Lhermet, "Amplified Piezoelectric Actuators for Aerospace Applications," AMAS Work. Smart Mater. Struct., pp. 51-63, 2003.

M. J. F. Bertin, C. R. Bowen, A. R. Plummer, and D. N. Johnston, "An Investigation of Piezoelectric Ring Benders and Their Potential for Actuating Servo Valves," in Proceedings of the Bath/ASME Symposium on Fluid Power and Motion Control, 2014, p. 6.

[7] Noliac, "Ring Benders," 2015. [Online]. Available: www.noliac.com. [Accessed: 01-Dec-2015].

[8] J. Persson, C. R. Bowen, A. R. Plummer, and P. L. Elliott, "Dynamic Modelling and Performance of a Two Stage Piezoelectric Servovalve," in Proceedings of the ASME 2016 9th FPNI Ph.D Symposium on Fluid Power, 2017, pp. 1-10.

[9] J. C. Jones and T. S. Manager, "Development in Design of Electrohydraulic Control Valves From Their Initial Design Concept to Present Day Design And Applications.” Moog Australia PTY LTD., pp. 1-19, 1997.

[10] Moog, "Electrohydraulic Valves... A Technical 
Look."

[11] Moog, "Type 26 Single Inlet Flow Control Servovalves," 2011.

[12] F. Stefanski, B. Minorowicz, J. Persson, A. Plummer, and C. Bowen, "Non-linear control of a hydraulic piezo-valve using a generalised Prandtl - Ishlinskii hysteresis model," Mech. Syst. Signal Process., vol. 82, pp. 412-431, 2017.

[13] M. Rakotondrabe, "Bouc - Wen Modeling and Inverse Multiplicative Structure Actuators to Compensate Hysteresis Nonlinearity in Piezoelectric Actuators," vol. 8, no. 2, pp. 428-431, 2011.

[14] D. K. Sangiah, "Fluid Metering Using Active Materials," University of Bath, 2011.

[15] K.-E. Rydberg, "Hydraulic Servo Systems." Linköpings Universitet, Linköping, 2008.

[16] Parker Hannifin - Electromechanical Automation Div., "Fundamentals of Servo Motion Control." 